EESTI NSV TEADUSTE AKADEEMIA TOIMETISED 1955. IV kd, nr. 1 ИЗВЕСТИЯ АКАДЕМИИ НАУК ЭСТОНСКОИ ССР 1955. Том IV, 시 1

\title{
ВЫСОКОТЕМПЕРАТУРНЫЙ СЛАНЦЕВЫЙ ГАЗ
}

\author{
И. И. СТЕПАНОВ, \\ кандидат технических наук

\section{1. Задачи исследования}

Сланцегазовая промышленность Прибалтийского бассейна за последние годы получила большое развитие. Более половины технологического сланца перерабатывается в настоящее время на газ.

Сланцевым газом снабжаются Ленинград, а также Таллин и некоторые другие города Әстонской ССР. Ставится вопрос о снабжении сланцевым газом городов Риги и Тарту и населенных пунктов, примыкающих к трассам магистральных газопроводов.

С целью получения максимального количества газа процесс термического разложения сланца проводится при высокой температуре. Получаемый при этом газ характеризуется высоким содержанием окиси углерода и водорода. Углеводородная часть сланцевого газа занимает. в общей смеси около ${ }^{1 / 3}$ объема, но сообщает газу до $70-80 \%$ общей теплотворности.

Химический состав газа, особенно его углеводородной части, является сложным и зависит от многих факторов, в том. числе от температурного режима, от способа эвакуации парогазовой смеси, от степени разложения органического вещества сланца и т. д.

Как показывают работы по исследованню сланцевого газа $(1,4,6)$, а также опыты автора, по мере прогрева кусковой загрузки сланца при изменении температуры внутренних стенок реторты от 850 до $950^{\circ}$ coстав газа закономерно изменяется. Концентрация углеводородов по мере прогрева сланца падает, и вместе с этим резко возрастает содержание окиси углерода. Что касается содержания углекислоты и водорода, то их концентрация не претерпевает столь больших изменений (табл. 1).

Процесс разложения горючего сланца усложняется одновременным протеканием многочисленных реакций, связанных с крекингом смолы, разложением углеводородов, а также минерального остатка.

Обычно газ термического разложения твердого топлива содержит 10-12 горючих компонентов различной теплотворной способности. Если водород и окись углерода имеют теплотворность $2580-3050$ ккал/нм ${ }^{3}$, то теплотворность высших углеводородов - бутана и бутилена в 10 раз больше - соответственно 31400 и 28800 ккал/нм³. Поэтому при оценке сланцевого газа необходимо знать детальный состав углеводородной 
Изменение состава высокотемпературного сланцевого газа по данным технического анализа

\begin{tabular}{c|c|c|c|c|c|c|c}
\hline $\begin{array}{c}\text { Время от начала } \\
\text { термического }\end{array}$ & \multicolumn{7}{|c}{ Состав газа в \% } \\
\cline { 2 - 7 } $\begin{array}{c}\text { ражления сланца } \\
\text { в час. }\end{array}$ & $\mathrm{CO}_{2}+\mathrm{H}_{2} \mathrm{~S}$ & $\mathrm{C}_{\mathrm{n}} \mathrm{H}_{\mathrm{m}}$ & $\mathrm{O}_{2}$ & $\mathrm{CO}$ & $\mathrm{H}_{2}$ & $\mathrm{C}_{\mathrm{n}} \mathrm{H}_{2 \mathrm{n}+2}$ & $\mathrm{~N}_{2}$ \\
\hline & 14,0 & 11,4 & 1,2 & 11,2 & 24,6 & 20,4 & 17,2 \\
$0-1$ & 16,5 & 5,7 & 1,5 & 14,5 & 28,1 & 18,5 & 15,2 \\
$1-2$ & 16,0 & 2,6 & 0,6 & 29,4 & 29,4 & 16,4 & 5,6 \\
$2-3$ & 17,4 & 1,1 & 0,2 & 42,0 & 20,0 & 8,5 & 10,8 \\
$3-4$ & 10,5 & 1,3 & 0,2 & 62,5 & 11,5 & 2,0 & 12,0 \\
$4-5$ & 8,6 & 0,2 & 0,2 & 75,6 & 9,8 & 2,5 & 3,1 \\
$5-6$ & & & & & &
\end{tabular}

части, так как только в этом случае можно судить об истинной теплотворности газа.

Углеводородные газы за последнее время нашли широкое применение для самых различных целей, как для синтеза, так и для выделения из них компонентов жидкого газа. Это обстоятельство также заставляет обратить самое пристальное внимание на состав углеводородной части сланцевого газа, тем более что имеющаяся в настоящее время литература по сланцевому газу не содержит в достаточной мере данных по составу углеводородной части.

Нами исследовался высокотемпературный газ бывшего Таллинского газового завода, где по технологическим условиям работы горизонтальной реторты системы Дидье представлялось возможным проследить постепенное разложение кускового сланца, изменение выхода и состава газа вплоть до полного исчерпывания летучей части сланца.

Термическое разложение сланца в действующих камерных печах протекает при тех же температурных условиях, т. е. при $750-800^{\circ}$. Однако режим работы в камерных печах осуществляется непрерывно, что затрудняет наблюдение постепенного изменения состава газа.

Настоящая работа ставит себе задачу полнее осветить процесс газообразования при высоких температурах.

Исследование газа с прнменением глубокого охлаждения и ректификации, в противоположность обычному техническому анализу, требует больших количеств газа. Проведение подобного исследования в лабораторных условиях вследствие этого весьма затруднительно.

В задачу проведенного нами исследования входило: 1) определение закономерности выхода отдельных компонентов газа в зависимости от продолжительности коксования, 2) определение изменения степени ненасыщенности отдельных углеводородных фракций газа $-\mathrm{C}_{2}, \mathrm{C}_{3}$ и $\mathrm{C}_{4}$, 3) определение оптимальных условий выхода отдельных компонентов газа.

\section{2. Характеристика высокотемпературного газа}

При проведении настоящих опытов отбор парогазовой смеси из зоны коксования осуществлялся на холодную сторону, ввиду чего в газ переходило $35-40 \%$ органического вещества сланца. Остальное количество распределялось примерно поровну между коксовым остатком и смолой.

Как показывает таблица 2, количественный выход газа во времени крайне неравномерен: за первые два часа коксования выделяется $75 \%$ всего газа, далее происходит резкое падение его выхода, которое совпа- 
дает с увеличением в нем концентрации окиси углерода. Наиболее резкое изменение претерпевает углеводородная часть сланца.

Таблица 2

Средний состав и выход отдельных компонентов высокотемпературного газа *

\begin{tabular}{|c|c|c|c|c|c|c|c|c|c|}
\hline \multirow{3}{*}{$\begin{array}{c}\text { Наимено- } \\
\text { вание компо- } \\
\text { нентов }\end{array}$} & \multicolumn{3}{|c|}{$\begin{array}{c}\text { Выход при высоко- } \\
\text { температурном раз- } \\
\text { ложении органи- } \\
\text { ческого вещества } \\
\text { в \% по объему }\end{array}$} & \multirow{3}{*}{$\begin{array}{c}\text { Выход } \\
\text { газа в } \\
\text { нм }^{3} / \mathrm{T}\end{array}$} & \multicolumn{3}{|c|}{$\begin{array}{c}\text { Выход при дококсо- } \\
\text { вывании остатка }\end{array}$} & \multirow{3}{*}{$\begin{array}{c}\text { Выход } \\
\text { газа в } \\
\text { нм }^{3} / \mathrm{T}\end{array}$} & \multirow{3}{*}{$\begin{array}{c}\text { Общий } \\
\text { выход в } \\
\text { нм }^{3} / \mathbf{T}\end{array}$} \\
\hline & \multicolumn{3}{|c|}{$\begin{array}{l}\text { Время от начала } \\
\text { разложения в час. }\end{array}$} & & \multicolumn{3}{|c|}{$\begin{array}{l}\text { Время от начала } \\
\text { разложения в час. }\end{array}$} & & \\
\hline & $0-1$ & $1-2$ & $2-3$ & & $3-4$ & $4-5$ & $5-6$ & & \\
\hline $\mathrm{CO}_{2}$ & 11,0 & 11,8 & 14,6 & 25,9 & 11,5 & 9,5 & 8,1 & 3,6 & 29,5 \\
\hline $\mathrm{H}_{2} \mathrm{~S}$ & 4,4 & 3,1 & 2,1 & 7,5 & 1,5 & 0,9 & 0,5 & 0,4 & 7,9 \\
\hline $\mathrm{C}_{2} \mathrm{H}_{4}$ & 8,6 & 4,2 & 3,1 & 12,4 & 1,2 & 1,0 & 0,2 & 0,4 & 12,8 \\
\hline $\mathrm{C}_{2} \mathrm{H}_{6}$ & 9,0 & 2,5 & 1,3 & 10,6 & 0,4 & 0,2 & - & 0,1 & 10,7 \\
\hline $\mathrm{C}_{3} \mathrm{H}_{6}$ & 5,2 & 2,2 & 1,5 & 6,0 & 0,3 & - & - & - & 6,0 \\
\hline $\mathrm{C}_{3} \mathrm{H}_{8}$ & 3,1 & 1,0 & 0,5 & 3,8 & 0,1 & - & - & - & 3,8 \\
\hline $\mathrm{C}_{4} \mathrm{H}_{8}$ & 2,5 & 1,4 & 0,8 & 3,7 & - & - & - & - & 3,7 \\
\hline $\mathrm{C}_{4} \mathrm{H}_{10}$ & 1,4 & 0,6 & 0,2 & 1,8 & - & - & - & - & 1,8 \\
\hline $\mathrm{CO}$ & 7,8 & 10,2 & 14,5 & 22,0 & 31,5 & 55,0 & 70,8 & 14,6 & 36,6 \\
\hline $\mathrm{H}_{2}$ & 15,3 & 24,6 & 29,0 & 46,9 & 27,5 & 15,0 & 9,8 & 7,6 & 54,5 \\
\hline $\mathrm{CH}_{4}$ & 14,2 & 17,5 & 18,0 & 35,1 & 10,0 & 6,5 & 2,0 & 2,6 & 37,7 \\
\hline $\mathrm{O}_{2}$ & 1,0 & 2,0 & 1,2 & 3,2 & 1,0 & 1,8 & 1,0 & 0,1 & 3,3 \\
\hline $\mathrm{N}_{2}$ & 15,0 & 17,1 & 12,4 & 34,1 & 15,0 & 10,1 & 7,6 & 4,3 & 38,4 \\
\hline $\mathrm{C}_{5}$ и выше & 1,5 & 1,8 & 0,8 & 3,3 & - & - & - & - & 3,3 \\
\hline $\begin{array}{c}\text { Выход в } \\
\text { нм }^{3} / \mathrm{T}\end{array}$ & 86,0 & 93,5 & 36,8 & 216,3 & 20,0 & 10,0 & 3,7 & 33,7 & 250,0 \\
\hline $\begin{array}{c}\text { Теплотвор- } \\
\text { ность газа } \\
\text { ккал/нм } / \mathrm{m}^{3}\end{array}$ & 7800 & 5480 & 4490 & 6200 & 3090 & 2940 & 2620 & 2980 & 5800 \\
\hline
\end{tabular}

Отдельные пробы газа были исследованы нами в интервалах через каждые 20 минут. При этом было замечено, что концентрация этилена на протяжении первых 60 минут оставалась примерно на одном и том же уровне, т. е. в пределах $8-10 \%$ по объему, после чего снижалась.

Более резкое снижение наблюдалось в отношении содержания в газе этана. Если в течение первых 20 минут разложения содержание его было одинаковым с содержанием этилена, т. е. 8-10\%, то в дальнейшем концентрация этана снижалась более резко.

Концентрация углеводородов $\mathrm{C}_{3}$ и $\mathrm{C}_{4}$, как термически менее стойких, снижается еще более резко. Бутан-бутиленовая фракция в газе начальной стадии разложения содержится в количестве $3-4 \%$, однако к третьему часу разложения фракция $\mathrm{C}_{4}$ в газе практически отсутствует.

Наличие в газе высокой концентрации высокомолекулярных углеводородов обусловливает значительную теплотворность сланцевого газа, составляющую в первый час разложения 7800 ккал/нм ${ }^{3}$, из которых около 5800 ккал приходится на высокомолекулярные углеводороды $\mathrm{C}_{2}, \mathrm{C}_{3}$ и $\mathrm{C}_{4}$

* Азот и кислород присутствуют в газе вследствие подсосов; фактический выход составляет 208,3. нм $3 /$ т газа повышенной теплотворности. 
(табл. 2). Доля тепла окиси углерода, водорода и метана при этом составляет всего около 200 ккал. Это обстоятельство свидетельствует о том, что газ начальной стадии разложения сланца характеризуется высоким содержанием углеводородных фракций $\mathrm{C}_{2}, \mathrm{C}_{3}$ и $\mathrm{C}_{4}$.

По мере прогрева загруженного сланца и исчерпывания органического вещества его вторичные процессы термического разложения приобретают все большее значение. Теплотворность газа в интервале 3-4-го часа разложения составляет 3090 ккал/нм³, из которых только 1290 ккал, т. е. $42 \%$, приходится на углеводородную часть. Практически газообразование прекращается на 4-5-м часу, причем в газе уже не содержится тяжелых углеводородов, и он имеет теплотворность 2940 ккал, из которых на углеводороды приходится 800 ккал, т. е. $27 \%$.

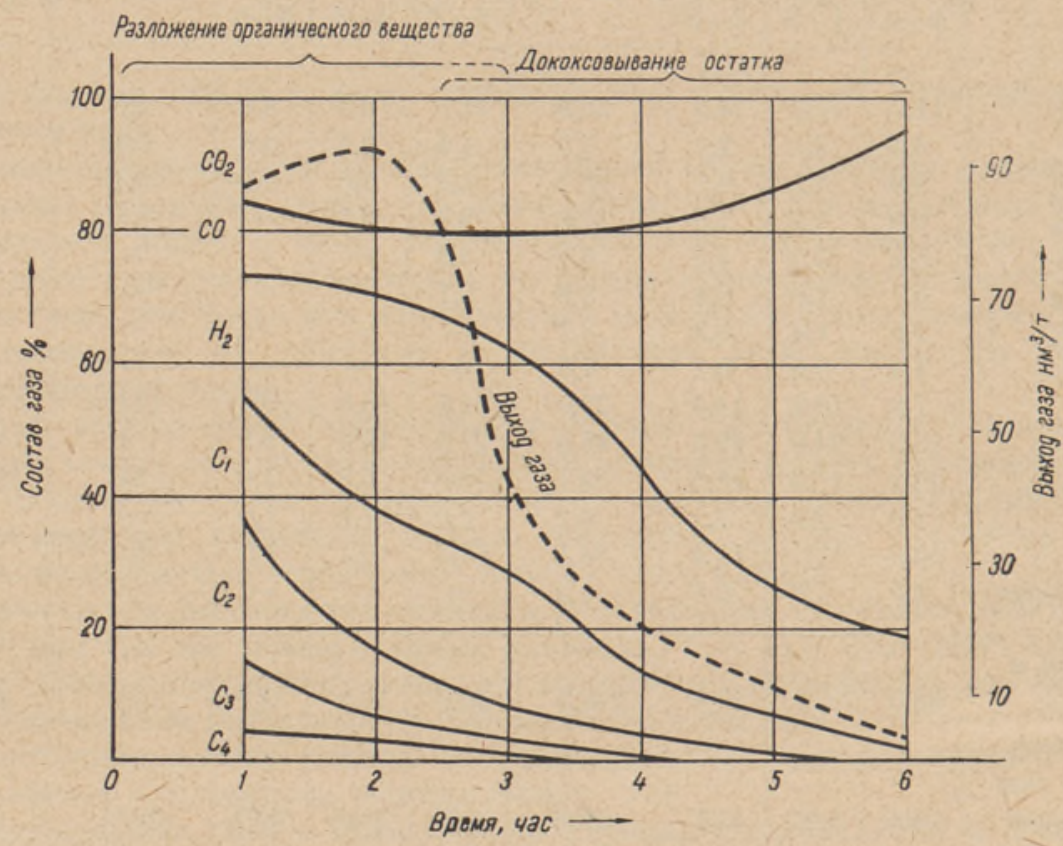

Фнг. 1. Изменение состава и выхода газа при высокотемпературном разложении сланца.

Дальнейшее дококсовывание коксового остатка приводит к незначительному выходу газа, основная масса которого состоит из окиси и двуокиси углерода, а также водорода.

Таким образом, из таблицы 2 видно, что высокотемпературное разложение сланца проходит как бы два этапа. Первый этап - интенсивный распад органического вещества сланца - характеризуется высокой концентрацией углеводородных компонентов. Этот этап разложения занимает в условиях настоящих опытов меньшую часть времени $-2,0-2,5$ часа. Второй этап - дококсовывание сланцевого коксового-остатка - продолжается 3-4 часа, однако, как сказано выше, на этом этапе образуется $20-25 \%$ от общего выхода газа пониженной теплотворности.

Характерно, что абсолютный выход окиси углерода при дококсовывании коксового остатка не снижается так резко, как выход других компонентов газа.

Несомненно, что граница между этими двумя этапами разложения чисто условная. В таблице 2 и на фиг. 1 эта граница определена временем исчерпывания в газе бутана и бутилена. Однако общие выводы мало из- 
менятся, если этот раздел провести между 1-2-м и 2-3-м часом разложения и сделать соответствующие пересчеты.

Фиг. 2 показывает изменение степени ненасыщенности отдельных углеводородных компонентов по мере разложения при высокой температуре. Из нее видно, что содержание непредельных углеводородов в газе может меняться в самых широких пределах. К концу разложения общая концентрация фракций $\mathrm{C}_{3}$ и $\mathrm{C}_{4}$ становится настолько незначительной, что затрудняет определение степени ненасыщенности, т. е. отношения непредельной части к общей сумме компонентов отдельной фракции газа.

Отдельные компоненты сообщают высокотемпературному сланцевому газу следующее количество тепла: $\mathrm{H}_{2}+\mathrm{CO}-20 \%, \mathrm{C}_{1}+\mathrm{C}_{2}-55 \%$, $\mathrm{C}_{3}+\mathrm{C}_{4}-25 \%$. Более половины всего тепла газа приходится на трн компонента газа - метан, этан и этилен.

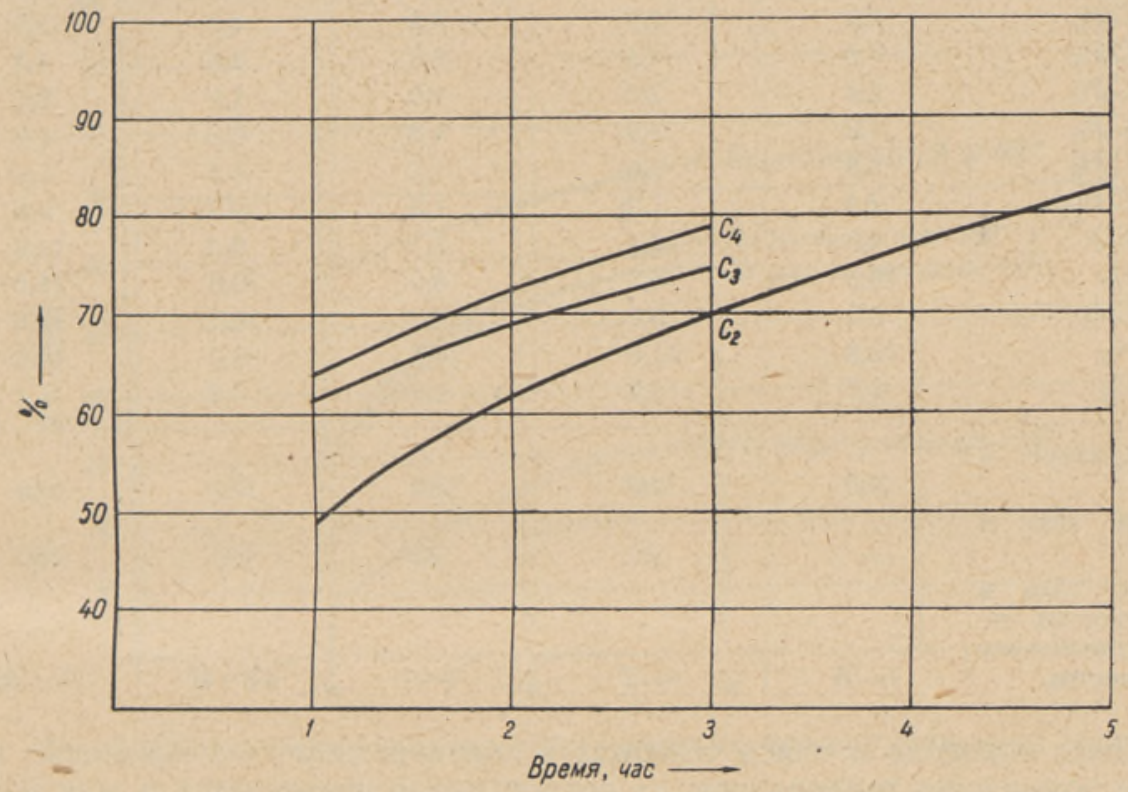

Фиг. 2. Изменение степени ненасыщенности углеводородных фракций сланцевого газа.

\section{3. Сравнение состава высокотемпературного газа с составом газов} других промышленных установок по переработке горючих сланцев

Данные о составе газа, полученного в самых различных температурных интервалах, начиная от $330^{\circ}$ и выше, приведены в таблице 3 .

Наиболее характерным для газа низкотемпературной переработки (газ из лабораторной реторты) является относительно высокая концентрация водорода. Если высокое содержание водорода в высокотемпературном газе объясняется разложением термически мало устойчивых углеводородов, то водород низкотемпературного газа обязан своим происхождением первичному разложению керогена.

Газ промышленной переработки сланца содержит большое количество подсосанного из атмосферы воздуха. При пересчете состава газа на безвоздушный видно, что по концентрации водорода газ вращающихся реторт ближе всего стоит к низкотемпературному газу. Однако выход газа в этих условиях невелик и составляет $6-7 \%$ по весу от органического вещества. 
По мере повышения температуры (туннельные печи) газ обогащается преимущественно углеводородными компонентами, так как разложение тяжелых углеводородов происходит по линии $\mathrm{C}-\mathrm{C}$ легче, чем по линии $\mathrm{C}-\mathrm{H}$.

Таблица 3

Основные данные о некоторых видах сланцевого газа (в \% по объему)

\begin{tabular}{|c|c|c|c|c|c|}
\hline $\begin{array}{c}\text { Наименования } \\
\text { компонентов }\end{array}$ & $\begin{array}{c}\text { Газ } \\
\text { лаборатор- } \\
\text { ных реторт }\end{array}$ & $\begin{array}{c}\text { Газ } \\
\text { вращающихся } \\
\text { реторт }\end{array}$ & $\begin{array}{c}\text { Газ } \\
\text { туннельных } \\
\text { печей }\end{array}$ & $\begin{array}{l}\text { Бытовой } \\
\text { газ }\end{array}$ & $\begin{array}{l}\text { Высоко- } \\
\text { температур- } \\
\text { ный газ }\end{array}$ \\
\hline $\mathrm{CO}_{2}$ & 25,4 & 12,6 & 16,6 & 16,1 & 13,0 \\
\hline $\mathrm{H}_{2} \mathrm{~S}$ & 6,5 & 4,7 & 8,5 & - & 3,1 \\
\hline $\mathrm{C}_{2} \mathrm{H}_{4}$ & 0,7 & 1,9 & . 3,5 & 4,0 & 5,2 \\
\hline $\mathrm{C}_{2} \mathrm{H}_{6}$ & 7,8 & 4,5 & 8,8 & 2,8 & 4,1 \\
\hline $\mathrm{C}_{3} \mathrm{H}_{6}$ & 2,4 & 2,0 & 4,6 & 1,0 & 2,4 \\
\hline $\mathrm{C}_{3} \mathrm{H}_{8}$ & 4,8 & 1,9 & 4,8 & 0,5 & 1,5 \\
\hline $\mathrm{C}_{4} \mathrm{H}_{8}$ & 1,8 & 1,6 & 1,8 & 0,5 & 1,4 \\
\hline $\mathrm{C}_{4} \mathrm{H}_{30}$ & 2,4 & 1,2 & 1,3 & 0,1 & 0,6 \\
\hline $\mathrm{CO}$ & 4,8 & 4,4 & 7,4 & 9,5 & 14,3 \\
\hline $\mathrm{H}_{2}$ & 18,9 & 5,5 & 5,6 & 20,6 & 21,5 \\
\hline $\mathrm{CH}_{4}$ & 9,0 & 5,5 & 9,6 & 14,3 & 15,0 \\
\hline $\mathrm{N}_{2}$ & 13,8 & 51,0 & 26,3 & 30,0 & 16,5 \\
\hline $\mathrm{O}_{2}$ & 1,7 & 3,2 & 1,2 & 0,6 & 1,4 \\
\hline $\begin{array}{l}\text { Tемпература в } \\
{ }^{\circ} \mathrm{C}\end{array}$ & 330 & 450 & 480 & 750 & 800 \\
\hline$\underset{\text { Hм }^{3 / T}}{\text { Выход газа в }}$ & - & 20 & 25 & 400 & 250 \\
\hline $\begin{array}{c}\text { Выход газа в } \\
\text { процентах от } \\
\text { органического } \\
\text { вещества }\end{array}$ & $5-6$ & $6-7$ & $8-9$ & $44-47$ & $35-40$ \\
\hline
\end{tabular}

Доля водорода и окиси углерода в полукоксовом газе невелика. По мере повышения температуры их концентрация повышается и, как показывает таблица 3, в высокотемпературном газе составляет до $40 \%$ по объему и больше.

Эта закономерность видна также из фиг. 3 , где показана степень ненасыщенности углеводородных фракций газа $\mathrm{C}_{2}, \mathrm{C}_{3}$ и $\mathrm{C}_{4}$.

Нижняя кривая для температурного режима в $330^{\circ}$ показывает, что в этих условиях образуются преимущественно углеводороды предельного характера. Фракция $\mathrm{C}_{2}$ всего на $8 \%$ состоит из этилена, остальное приходится на этан, которого в газе содержится $7,8 \%$ по объему (табл. 3 ).

По мере повышения температуры степень ненасыщенности углеводородных фракций увеличивается. Выше всего проходит кривая высокотемпературного газа, в котором фракция $\mathrm{C}_{2}$ на $60 \%$ состоит из этилена. Отсюда видно, что эти условия ңаиболее благоприятны для образования водорода и метана.

При температурах полукоксования $450^{\circ}$ и ниже образуются преимущественно насыщенные углеводороды с высокой концентрацией этана.

При температуре $330^{\circ}$ начинается процесс разложения органического вещества сланца. Образующийся при этом газ характеризуется, как уже сказано выше, высокой концентрацией водорода и углеводородов предельного характера. Это обстоятельство связано с разложением молекулы керогена сланца. 
Аналогичное явление наблюдается и при термическом разложении некоторых нефтей и объясняется наличием в них нафтеновых углеводородов $\left({ }^{5}\right)$.

Из данных таблицы 3 видно, что выход бытового газа в камерных печах значительно выше, что объясняется различием в технологических режимах переработки $\left({ }^{2}\right)$. В камерных печах, как известно, образующаяся парогазовая смесь эвакуируется на горячую сторону, проходя раскаленный слой сланцевого кокса. Вследствие этого выход газа в этих печах значительно увеличивается, и фактический выход горючих компонентов также выше, чем в высокотемпературном газе бывшего Таллинского газового завода, где отбор парогазовой смеси проходил на холодную сторону.

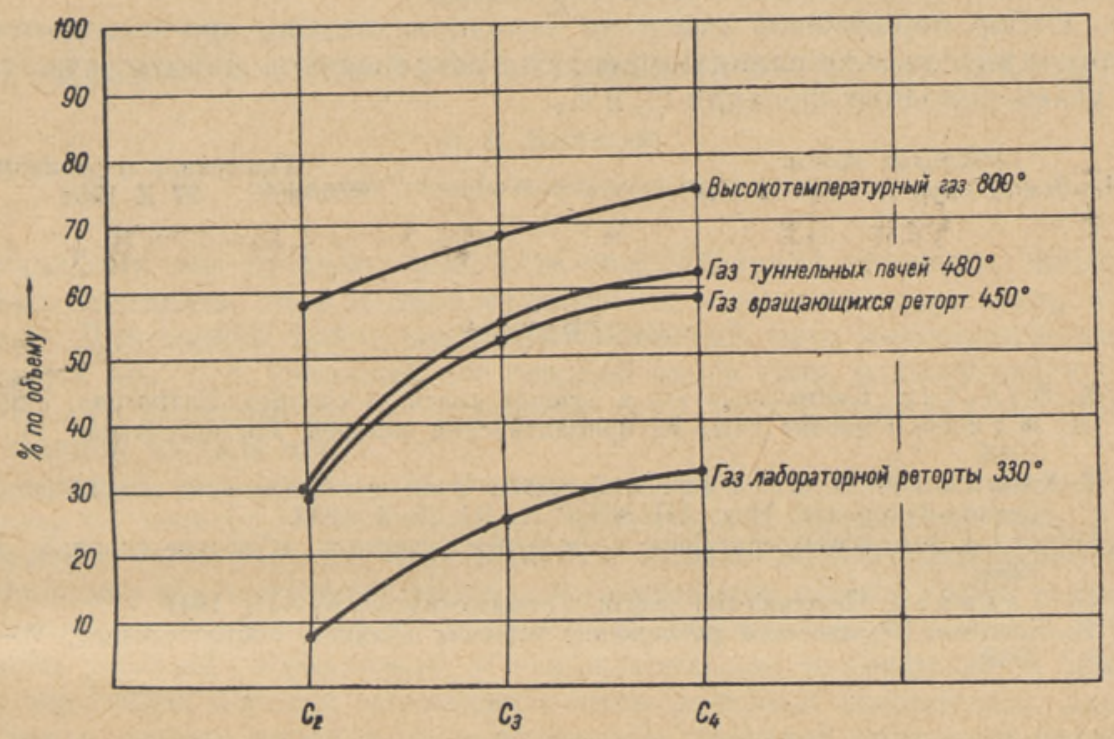

Фиг. 3. Степень ненасыщенности углеводородных фракций сланцевого газа.

Исключением являются компоненты $\mathrm{C}_{3}$ и $\mathrm{C}_{4}$, общий выход которых в расчете на состав бытового газа камерных печей составляет $5,6 \mathrm{Hм}^{3} / \mathrm{T}$. Выход фракции $\mathrm{C}_{3}+\mathrm{C}_{4}$ в высокотемпературном газе Таллинского газового завода составляет $12,2 \mathrm{Hм}^{3} /$ т. Однако при этом следует учесть, что бытовой газ проходит тщательную очистку и отбензинование, что, несомненно, связано с удалением из него части фракции $\mathrm{C}_{3}+\mathrm{C}_{4}$. Пробы же высокотемпературного газа взяты непосредственно на печи и содержат не только компоненты $\mathrm{C}_{3}$ и $\mathrm{C}_{4}$, но и газовый бензин. Этот факт указывает и на то, что, несмотря на уменьшение общего выхода газа при отборе парогазовой смеси на холодную сторону, в нем сохраняются ценные фракции $\mathrm{C}_{3}$ и $\mathrm{C}_{4}$, могущие найти применение в качестве жидкого газа.

\section{Выводы}

1. Высокотемпературное разложение кускового сланца протекает с интенсивным выделением газа. Начальная стадия газообразования характеризуется высокой концентрацией углеводородных фракций $\mathrm{C}_{2}, \mathrm{C}_{3}$ и $\mathrm{C}_{4}$.

Дококсовывание сланцевого полукоксового остатка характеризуется низким выходом газа, состоящего преимущественно из $\mathrm{CO}, \mathrm{H}_{2}$ и $\mathrm{CO}_{2}$. Из углеводородов при этом образуются преимущественно $\mathrm{CH}_{4}$ и $\mathrm{C}_{2} \mathrm{H}_{4}$. 
2. Углеводородные фракции высокотемпературного газа характеризуются высокой степенью ненасыщенности. 60-70\% фракции $\mathrm{C}_{2}$ приходится на этилен. Концентрация пропилена и бутилена во фракциях $\mathrm{C}_{3}$ и $\mathrm{C}_{4}$ соответственно еще выше.

По этому показателю высокотемпературный газ принципиально отличается от газа полукоксования.

3. Высокая концентрация в газе водорода при высокотемпературном разложении сланца объясняется крекингом углеводородных компонентов и находится в связи с высокой степенью ненасыщенности углеводородных фракций.

Относительно высокая концентрация водорода при начальной стадии разложения сланца, при низких температурах, объясняется первичным разложением органического вещества сланца.

4. Отбор парогазовой смеси на холодную сторону при высокотемпературном разложении сланца приводит к сохранению в составе газа тяжелых углеводородных фракций $\mathrm{C}_{3}$ и $\mathrm{C}_{4}$.

\section{Институт химии \\ Академии наук Эстонской ССР \\ Поступила в редакцию $27 \times 1954$}

\section{ЛИТЕРАТУРА}

1. В. К. В альги с, Светильный газ и газовая смесь из сланцев, Петроград, 1920.

2. В. И. Ж унко, Горючие газы из прибалтийских сланцев, Гостоптехиздат, М.-Л., 1948.

3. А. Т. К ыл ль и И. И. С т е п а о в, О составе газа промышленного полукоксования сланца-кукерсита, Изв. АН ЭССР, т. III, № 3, 1954.

4. А. П у к сов, Высокотемпературное разложение кукерсита, «Горючие сланцы», № 1 , 1934.

5. А. Н. С а х а не н, Переработка нефти, Гостоптехиздат, М.-Л., 1947.

6. Я. И. Хи с и н, Термическое разложение горючнх сланцев, Гостоптехиздат, М.-Л., 1948. 